\title{
Editorial
}

\section{What is our work worth?}

Value is a theme that's become critical. It has various aspects, such as evaluation of the work of public health nutrition professionals, appraisal of the system and structure within which we work, and the perceived value of our profession.

\section{Our own commitments and needs}

In their critique of the effectiveness of international action to address undernutrition, Saul Morris and colleagues ${ }^{(1)}$ have highlighted the role that journal editors can play to 'increase the profile and programmatic relevance of the topic and to reduce fragmentation'.

As one priority, John Waterlow has asked us to pay more attention to undernutrition ${ }^{(2)}$, as we will ${ }^{(3)}$. Another priority is papers that themselves include evaluation of work done. Over the years we have published a few reviews of the evidence but not enough in the form of original papers. We want more of these.

We also need to address why there is relatively little data collected on the effectiveness of programmes around the world. Funding for evaluation is neglected. Also, there is too little attention paid to the infrastructure and staff skills required to undertake, collect and analyse relevant data. We also need to share best practice about how to strengthen our workforce, as we did in the August issue ${ }^{(4)}$. And we need to continue to publish the best quality evidence about the underlying and basic economic, social - including political - and environmental drivers of public health nutrition status.

\section{WHO, nutrition and nutritionists}

Margaret Chan, Director-General of the WHO, has been speaking to us. Her address, 'The global nutrition challenge', given at the Pacific Health Summit in Seattle in June, is a challenge to public health nutrition practitioners ${ }^{(5)}$.

Dr Chan highlighted issues we have already raised about the impact of soaring world food prices, and food and nutrition leadership and policy ${ }^{(6)}$. In addressing global leadership in nutrition she said:

I see two main areas where leadership is needed, and can make a significant difference for health. First, we need leadership to deliver interventions for nutritional deficiencies to those in greatest need. The interventions already exist. They are cost-effective, and many bring spectacular results. Here, the need is for leadership and innovative in devising delivery systems.
Second, leadership is needed to ensure that policies governing agriculture, food production, and trade are firmly anchored in human nutritional needs and are shaped by health concerns. This is a need for political leadership.

She continues:

A discussion of leadership, especially at the policy level, must take a hard look at the current food crisis. We must understand where policies that paid insufficient attention to health have led us.

\section{Are we on board?}

The leadership Dr Chan calls for focuses on how to ensure policy is joined up and delivers effective action. To date public health nutritionists have identified the problems, but are we engaged sufficiently in the way Dr Chan suggests? Her speech is a challenge to us because, in addressing big picture issues, she does not specifically mention the role of nutrition professionals. There is no discussion of workforce development and capacity. Leadership is required, but so too is a workforce to deliver the programmes. If the nutrition profession is not seen to be relevant to deliver this, why not? Surely we should be? I have said earlier in this editorial that Public Health Nutrition wants to encourage more scholarship in programme delivery, but we must also see how we can support the workforce to deliver these programmes. Researchers, teachers and programme staff need to work closely together to ensure that the research we do, the people we train and the service we undertake are mutually supportive and reinforcing. If we don't want to be seen to be irrelevant we have to engage and show that we can make a difference. It is important to highlight problems, but we also have to show that we can be part of the solution as well. Are we on board?

Barrie Margetts Deputy Editor

\section{References}

1. Morris S, Cogill B \& Uauy R (2008) Effective international action against undernutrition: why has it proven so difficult and what can be done to accelerate progress? Lancet $\mathbf{3 7 1}$, 608-621.

2. Waterlow J (2008) Undernutrition should be the first priority. Public Health Nutr 11, 651. 
3. Margetts B (2008) What we should be saying - and doing - about undernutrition. Public Health Nutr 11, 547-548.

4. Hughes R (2008) Workforce development challenges for practice, professionalization and progress. Public Health Nutr 11, 765-767.

Public Health Nutrition: 11(10), 984

\section{In this issue}

New conceptual frameworks and ideas that challenge our ways of thinking about problems and issues are important. Public health nutrition is a field of practice and research that has a strong focus on change and change processes. We identify and seek to understand nutrition problems, the determinants and strategy options available, and work towards changing the social, economic, environmental and personal factors that work against optimal nutrition. If only it was that easy. Effectively implementing change is one of our perennial challenges. In this issue, McLachlan and Garrett $^{(1)}$ present a paper describing a descriptive framework of the orders of change and a change model (Theory $\mathrm{U})$. It should be required reading, if not to change the way we consider and plan for change, then to help categorise and order our approach to change in practice.

Early intervention and upstream focus are consistent features of a preventive approach. This means that pregnancy, infancy and childhood are critical life-stages for public health nutrition intervention, monitoring and research. Hong et al. ${ }^{(2)}$ present results from a prospective cohort study of Koreans investigating the association of maternal micronutrient status (vitamins A, C and E, folate) and oxidative stress status in pregnancy with infant growth during the first year of life. Their analysis suggests the importance of preventing folate deficiency and supplementing vitamin $\mathrm{C}$ during pregnancy.

Kosti et al. ${ }^{(3)}$ present findings from a cross-sectional study of cereal consumption among Greek schoolchildren and explore associations with obesity. Their analysis provides intelligence that may be applicable to further developing obesity prevention and management strategies and guidance.

Clark et $a l^{(4)}$ present a study that compares parents' self-reported child-feeding behaviours in two socioeconomically contrasting areas in the UK. Not surprisingly, child-feeding behaviours differed between areas within a single city and within a largely white population, reinforcing the evidence for the critical role of socioeconomic and educational factors in child nutrition.
5. Chan M (2008). The global nutrition challenge: getting a healthy start. Keynote address at the Pacific Health Summit, Seattle, WA, USA, 18 June 2008. http://www.who.int/dg/ speeches/2008/20080618/en/print.html (accessed June 2008).

6. Margetts B (2008) Food prices, inequity, and our responsibilities. Public Health Nutr 11, 437-438.

doi:10.1017/S1368980008003637

The importance of the food supply and other environmental determinants of nutritional status and food choice seems obvious. Research by Walker et al. ${ }^{(5)}$ in this issue quantifies what many Australian consumers have long experienced and what nutritionists have long lamented: that our food choice environment is biased towards a huge array of choice of products that fail to meet nutritional quality standards (read junk food!).

They suggest that the supply balance needs to be shifted in favour of 'healthier' snack foods and beverages by reformulation of many products by the food industry and their presentation in smaller, standardised, portionsize packaging. This somewhat optimistic suggestion brings me back to McLachlan and Garrett's paper about nutrition change strategies. It is rarely enough to know what needs to change. Effectively achieving change such as that proposed by Walker and colleagues remains the core challenge for public health nutrition as a discipline.

Roger Hughes Deputy Editor

\section{References}

1. McLachlan M \& Garrett J (2008) Nutrition change strategies: the new frontier. Public Health Nutr 11, 1063-1075.

2. Hong J, Park AE, Kim Y-J, Lee HY, Park B-H, Ha E-H, Kong KA \& Park H (2008) Association of antioxidant vitamins and oxidative stress levels in pregnancy with infant growth during the first year of life. Public Health Nutr 11, 998-1005.

3. Kosti RI, Panagiotakos DB, Zampelas A, Mihas C, Alevizos A, Leonard C, Tountas Y \& Mariolis A (2008) The association between consumption of breakfast cereals and BMI in schoolchildren aged 12-17 years: The VYRONAS study. Public Health Nutr 11, 1015-1021.

4. Clark HR, Goyder E, Bissell P, Blank L, Walters SJ \& Peters J (2008) A pilot survey of socio-economic differences in child-feeding behaviours among parents of primary-school children. Public Health Nutr 11, 1030-1036.

5. Walker KZ, Woods JL, Rickard CA \& Wong CK (2008) Product variety in Australian snacks and drinks: how can the consumer make a healthy choice? Public Health Nutr 11, 1046-1053. 